\title{
Seropositivity of Toxoplasmosis in Antenatal Women with Bad Obstetric History in a Tertiary-care Hospital of Andhra Pradesh, India
}

\author{
Munmun Das Sarkar', B. Anuradha², Neelam Sharma², and Rabindra Nath Roy' \\ 'Burdwan Medical College, Burdwan, West Bengal, India and ${ }^{2}$ Mamata Medical College, Khammam, Andhra Pradesh, India
}

\begin{abstract}
Toxoplasmosis is a well-documented cause of bad obstetric history (BOH) and a major reason of congenitally-acquired infection. The study was conducted to determine the seropositivity of toxoplasmosis in women with $\mathrm{BOH}$, attending the antenatal clinic of the Mamata General Hospital, Khammam, Andhra Pradesh, India. The study subjects included 105 antenatal women with $\mathrm{BOH}$ and 105 antenatal women who had previous normal deliveries. A serological evaluation was carried out to determine the presence of Toxoplasma gondii-specific IgG and IgM antibodies, using commercial diagnostic kits, by the enzyme-linked immunosorbent assay method. The seropositivity for Toxoplasma was $49.52 \%$ in the study group compared to $12.38 \%$ in the control group. The difference in seropositivity was significant $(\mathrm{p}=0.00)$. The seroprevalence gradually increased with advancing age. Abortion (51.92\%) was the commonest form of pregnancy wastage, followed by stillbirths (36.53\%) and premature deliveries (7.69\%). The seropositivity of toxoplasmosis was significantly higher in the study group than that in the control group, and the seropositivity played an important role in determining the foetal outcome. Considering the subclinical pattern of infection, routine serological test is recommended for all pregnant women for both IgG and IgM antibodies.
\end{abstract}

Key words: Bad obstetric history; Case-control studies; Descriptive studies; Seroprevalence; Toxoplasma gondii; Toxoplasmosis; India

\section{INTRODUCTION}

Toxoplasmosis is caused by an obligate intracellular protozoan parasite Toxoplasma gondii (1). It is one of the most common parasitic infections of humans and other warm-blooded animals. Approximately one-third of the population are exposed to this parasite (2). Infection in an immunocompetent adult human is usually asymptomatic. Toxoplasmosis is most dangerous for immunocompromised patients and the foetus whose mother is infected during pregnancy (3).

Transmission of the infection to the foetus usually occurs when primary infection is acquired by an immunologically-normal mother during gestation (4). Infected pregnant women are often asymptomatic or many have only mild symptoms, making the diagnosis difficult $(1,3)$. The organism is

Correspondence and reprint requests should be addressed to:

Dr. Munmun Das Sarkar

Ideal Apartment, Flat 2D, Block A

152 Raja R.L. Mitra Road

Kolkata 700 010, West Bengal

India

Email: drmdsarkar@hotmail.com transmitted haematogenously to the placenta. When this occurs, infection may be transmitted to the foetus transplacentally or during vaginal delivery (4). The risk of congenital toxoplasmosis depends on the timing of the mother's acute infection. The disease is usually severe when acquired in the first trimester, and the severity decreases as the gestational age advances, leading to a mild or an inapparent disease at birth. The different rates of transmission and outcomes are most likely related to placental blood-flow, the virulence and amount of $T$. gondii acquired, and the immunologic ability of the mother to restrict parasitaemia (4). The overall rate of transmission of maternal infection to the foetus is about $45 \%$. Of these, $60 \%$ are subclinical infections, $9 \%$ resulting in death of the foetus, and $30 \%$ have severe damage (5).

The clinical implications of infection due to Toxoplasma in pregnant patients are manifold. Such patients may have spontaneous abortions, stillbirths, intrauterine growth retardation, preterm deliveries, or foetal anomalies (6).

Various manifestations of congenital infection may occur in the perinatal period. These range from relatively-mild signs, such as prematurity, peripheral 
retinal scars, sensory deficits, developmental delay, impaired psychomotor performance, and mental retardation to the classic triad of signs consisting of hydrocephalus, intracerebral calcification, and chorioretinitis $(4,7)$.

Toxoplasmosis is, thus, a significant risk factor for bad obstetric outcome and a major cause of congenitally-acquired infection, leading to a high degree of intrauterine foetal death and morbidity of the newborn. Treatment of a pregnant woman who acquires infection at any time during pregnancy reduces the chance of congenital infection in her infant by approximately $60 \%$ (4). Therefore, early diagnosis of toxoplasmosis is essential to start appropriate treatment on time to reduce the transplacental transmission.

Toxoplasmosis is usually diagnosed by serological tests for Toxoplasma-specific IgM and IgG antibodies. A positive IgG titre is sufficient to establish that a patient has been infected with $T$. gondii but a negative IgM result virtually rules out a recentlyacquired infection, unless sera are tested so early when an antibody response has not yet developed or is undetectable (2).

Against this background, we attempted to determine the extent of seropositivity of toxoplasmosis in antenatal women with bad obstetric history $(\mathrm{BOH})$ and to compare it with that in antenatal women having previous normal obstetric history, attending the antenatal clinic of a tertiary-care hospital in Khammam, Andhra Pradesh, India.

\section{MATERIALS AND METHODS}

\section{Study area}

This descriptive case-control study was conducted in 2007 at the antenatal clinic of the Mamata General Hospital which is a super-specialty rural hospital attached to the Mamata Medical College, Khammam, Andhra Pradesh, India.

\section{Study subjects}

The study group comprised antenatal women of reproductive age with previous $\mathrm{BOH}$, including unfavourable foetal outcome in terms of abortions, intrauterine foetal death, stillbirths, preterm deliveries, unexplained early neonatal death, and congenital anomalies. The control group comprised multiparous, age-matched antenatal women without $\mathrm{BOH}$ attending the same clinic.

\section{Sample-size}

To work out the required sample-size for the determination of seropositivity in antenatal women with $\mathrm{BOH}$, the equation suggested by Vaughan and Mor- row was used (8). Considering 49.47\% seropositivity of toxoplasmosis in women with $\mathrm{BOH}(6), 10 \%$ margin of sampling error, and 1\% non-response rate, the desired sample-size was 105. About 2,210 pregnant women attended the antenatal clinic of the hospital in the previous year. Of these women, 125 presented with $\mathrm{BOH}$. Considering the admission trend, the investigators expected to obtain the desired sample within 10 months. In total, 210 women were included in the study-105 with $\mathrm{BOH}$ (study group) and 105 without $\mathrm{BOH}$ (control group).

\section{Collection of data}

The designated investigators visited the outpatient department on alternate day, selected the study subjects, and screened them using a predesigned pretested schedule considering the inclusion and exclusion criteria till 105 study subjects could be identified. The next available age-matched multiparous antenatal woman without $\mathrm{BOH}$ was included in the control group subjects.

Clinical examination and laboratory investigations were carried out for the study subjects to exclude other causes of foetal wastage, such as hypertension, diabetes mellitus, syphilis, Rh (rhesus) incompatibility, physical causes of abortion, and consanguinity. Subjects with known causes of foetal wastage were excluded from the study. All of them were interviewed to ascertain age, medical and obstetric information.

For serological analysis, $2 \mathrm{~mL}$ of venous blood was collected in a sterile container with strict aseptic precautions from each study subject. The serum was separated and stored in numbered aliquots at $-20{ }^{\circ} \mathrm{C}$ till assayed. All the serum samples collected from the study and control groups were tested for Toxoplasma IgM and IgG antibodies by commercially-available (ELISA) kits (98\% sensitivity, 98\% specificity) (Equipar Diagnostici, via G. Ferrari, 21/N 21047 Saronno (Va), Italy). The results were read by a Microwell reader and compared in a parallel manner with controls; optical density was read at $450 \mathrm{~nm}$ on an ELISA reader.

\section{Analysis of data}

Collected data were compiled in Microsoft Excel spreadsheet. The proportion and the mean value were computed in appropriate situations. To find out any association between categorical data, chisquare test was employed using the Epi Info software (version 3.5.1).

\section{Ethical approval}

The ethical committee of the concerned institute approved the research protocol. The purpose and 
procedures of the study were explained to all the study subjects, and informed consent was obtained from them.

\section{RESULTS}

\section{Seropositivity among study and control groups}

Table 1 shows that $49.52 \%$ were seropositive cases in the study group and $12.38 \%$ in the control group. The seropositivity of IgG alone was observed in $27.61 \%$ and $9.52 \%$ of the study and the control group subjects respectively. In the study group, $21.9 \%$ of the subjects were positive for both IgG and IgM antibodies while it was $2.86 \%$ in the control group. None was positive for IgM antibody alone. The difference in seropositivity was significant $(\mathrm{p}=0.00)$. enced $\mathrm{BOH}$ revealed that the highest percentages (52.38\%) of positivity was noted among women with a history of two $\mathrm{BOH}$, followed by $50 \%$ positivity among women with three or more $\mathrm{BOH}$, and the lowest (47.27\%) among women having one $\mathrm{BOH}$ (Table 3). The difference was not significant $(\mathrm{p}=0.88)$.

\section{Seropositivity in relation to type of bad obstetric history}

The seropositive cases were distributed in relation to the type of $\mathrm{BOH}$ (Table 4). It revealed that abortion $(51.92 \%)$ was the commonest form of pregnancy wastage, followed by stillbirths (36.53\%), premature deliveries (7.69\%), congenital anomalies $(1.93 \%)$, and early unexplained neonatal deaths $(1.93 \%)$.

\begin{tabular}{|lcccc|}
\hline \multicolumn{4}{|l|}{ Table 1. Seropositivity among study and control groups } \\
\hline Group & No. of cases & $\begin{array}{c}\text { No. (\%) of cases } \\
\text { positive for IgG } \\
\text { only }\end{array}$ & $\begin{array}{c}\text { No. (\%) of cases } \\
\text { positive for both IgG } \\
\text { and IgM }\end{array}$ & $\begin{array}{c}\text { Total no. (\%) of } \\
\text { seropositive cases }\end{array}$ \\
\hline $\begin{array}{l}\text { Study } \\
\text { Control }\end{array}$ & 105 & $29(27.61)$ & $23(21.9)$ & $52(49.52)$ \\
\hline $\begin{array}{l}\text { *None of the subjects was positive for IgM only in both the groups; Odds ratio=6.94; } \chi^{2}=33.89 \\
\text { (among total seropositive cases); } \text { df=1, p=0.00; df=Degree of freedom }\end{array}$ \\
\hline
\end{tabular}

Seropositivity in relation to age of subjects

The seropositivity was analyzed in relation to the age of the study subjects (Table 2). It was observed that the seropositivity increased with advancing age in both the groups. The seropositivity rate varied from $25 \%$ to $60.71 \%$ in the study group and from $0 \%$ to $17.64 \%$ in the control group. The z-test was applied to examine the significance of difference in the proportion of seropositivity between the two groups. The differences were not significant for the age-group of up to 25 years; however, the differences were significant for the age-groups of above 25 years.

\section{Seropositivity in relation to number of bad obstetric outcome}

The seropositivity of Toxoplasma in relation to the number of times the antenatal woman experi-

\section{DISCUSSION}

Toxoplasmosis is a zoonotic disease with worldwide distribution. Most Toxoplasma-associated infections among people occur by ingesting tissue cysts from infected meat or oocysts from soil or by congenital transmission through the placenta. The seropositivity levels vary widely in different regions of the globe. The rates of prevalence change according to the nutritional factors, sociocultural habits, geographic factors, climate, and transmission route and typically rise with age (9).

Interpretation of Toxoplasma serology was done according to Burrow and Duffy (10); when a positive IgM test result indicates acute/early infection, IgG titres should be retested in several weeks. A positive IgG titre is sufficient to establish that a patient has been infected with T. gondii. Recent infection is

\begin{tabular}{|c|c|c|c|c|c|c|c|}
\hline \multirow{3}{*}{ Age (years) } & \multicolumn{3}{|c|}{ Study group } & \multicolumn{3}{|c|}{ Control group } & \multirow{3}{*}{$\begin{array}{c}\mathrm{z} \text { and } \\
\mathrm{p} \text { value }\end{array}$} \\
\hline & \multirow{2}{*}{ Sera tested } & \multicolumn{2}{|c|}{ Positive sera } & \multirow{2}{*}{ Sera tested } & \multicolumn{2}{|c|}{ Positive sera } & \\
\hline & & No. & $\%$ & & No. & $\%$ & \\
\hline$\leq 20$ & 12 & 3 & 25.00 & 7 & 0 & 0.00 & $0.60(0.27)$ \\
\hline $21-25$ & 26 & 10 & 38.46 & 46 & 5 & 10.86 & $0.89(0.18)$ \\
\hline $26-30$ & 39 & 22 & 56.41 & 35 & 5 & 14.28 & $2.56(0.00)$ \\
\hline$>30$ & 28 & 17 & 60.71 & 17 & 3 & 17.64 & $2.04(0.02)$ \\
\hline
\end{tabular}




\begin{tabular}{|c|c|c|c|c|c|}
\hline \multirow{2}{*}{$\begin{array}{l}\text { No. of times with bad } \\
\text { obstetric outcome }\end{array}$} & \multirow{2}{*}{$\begin{array}{c}\text { No. of } \\
\text { sera tested }\end{array}$} & \multicolumn{2}{|c|}{ Seropositive } & \multicolumn{2}{|c|}{ Seronegative } \\
\hline & & No. & $\%$ & No. & $\%$ \\
\hline 1 & 55 & 26 & 47.27 & 29 & 52.72 \\
\hline 2 & 42 & 22 & 52.38 & 20 & 47.61 \\
\hline 3 and more & 8 & 4 & 50.00 & 4 & 50.00 \\
\hline
\end{tabular}

indicated by a positive test result for both IgG and IgM, and remote infection is usually indicated by a negative IgM with the positive IgG test result.

The prevalence of this infection reported in different studies in India shows a wide variation, and one pilot study on women in Kumaon region in 1991 reported the prevalence of $77 \%$, the highest reported so far in India (11). A recent pilot study in the same region in 2005 reported 55\% for Toxoplasma IgG antibodies and 20\% for IgM antibodies (12). Singh et al. found an overall anti-Toxoplasma IgG seroprevalence of $45 \%$ among pregnant women in New Delhi (13).

We analyzed the odds ratio (6.94) to estimate the risk of adverse pregnancy outcome associated with exposures to toxoplasmosis. This suggests a possible causal relationship between $T$. gondii-associated infection and $\mathrm{BOH}$. In our study, the overall seroprevalence of toxoplasmosis was $49.52 \%$ among antenatal women with $\mathrm{BOH}$ compared to $12.38 \%$ in the control group (Table 1). The compatible seropositivity of $49.47 \%$ in the study group and $8.88 \%$ in the control group was reported by Zargar et al. (6). Borkakoty et al. reported the seroprevalence of $44.6 \%$ and $36.8 \%$ among the study and the control group respectively (14). However, Singh and Dangvela observed an overall incidence of $13.3 \%$ in the study group and $4.0 \%$ in the control group (15). Results of a study by Bachhiwal et al. showed that the overall seroprevalence of toxoplasmosis was $22 \%(55 / 250)$ among study subjects. In the control group, it was $2 \%(1 / 50)$. The difference was also significant (16).

In the present study, $27.61 \%$ of the women were positive for IgG only, indicating remote infection, and $21.9 \%$ were positive for both IgG and IgM, indicating recent infection. A similar result was reported from a study in Hyderabad in 2001. Of 13 serum samples screened, the positivity for IgG was $43.3 \%$, and the positivity for both IgG and IgM was $32 \%$ (17). The same investigators performed another similar study in 2004 and analyzed 100 serum samples, which revealed that $33 \%, 5 \%$, and $18.2 \%$ of samples were positive for IgG, IgM, and both IgG and IgM respectively (18). A study in Manipur also recorded the seropositivity of $58.14 \%$ for
IgG, $2.32 \%$ for $\operatorname{IgM}$, and $6.97 \%$ for both $\operatorname{IgG}$ and $\operatorname{IgM}(19)$.

In the control group of the present study, the seropositivity of IgG, indicating remote infection, was $9.52 \%$, and it was $2.86 \%$ for both IgG and IgM, indicating recent infection (Table 1). Sandhu et al. detected 8\% IgG seropositivity among antenatal women without $\mathrm{BOH}$, and none of them was positive for IgM (20). Borkakoty et al. also observed the IgG seroprevalence of $36.8 \%$ among pregnant women without history of pregnancy wastage; in addition, the IgM seroprevalence was 5.9\% among the same group (14).

The percentage of seropositivity of toxoplasmosis demonstrated a gradual increase with advancing age of the mother, and the percentage was the highest among women of age-group of $>30$ years in our study (Table 2). Spalding et al. also observed a higher prevalence among people aged 20-30 years, and the prevalence of infection was increasing with older age-group (21). Mittal et al. opined that the seropositivity of Toxoplasma increases with age. According to their study, the lowest rate of antibody acquisition occurred in the age-group of 15-20 years; it increased with the increase in age; and the maximum prevalence was observed among women aged 36 years and above (22). Borkakoty et al. have also shown that the higher prevalence of infection due to $T$. gondii was associated with increase in age (14). This may be due to the fact that the frequency of infection increases with older age-groups as the probability of an individual coming into contact

\begin{tabular}{|lcc|}
\hline \multicolumn{3}{|c|}{$\begin{array}{c}\text { Table } \\
\text { 4.Seropositivity in relation } \\
\text { bad obstetric history }\end{array}$} \\
\hline $\begin{array}{l}\text { Type of bad } \\
\text { obstetric history }\end{array}$ & $\begin{array}{c}\text { Seropositive } \\
(\mathrm{n}=52)\end{array}$ & $\begin{array}{c}\% \\
(\mathrm{n}=52)\end{array}$ \\
\hline Abortion & 27 & 51.92 \\
IUFD/stillbirth & 19 & 36.53 \\
$\begin{array}{l}\text { Premature delivery } \\
\text { Abortion and }\end{array}$ & 4 & 7.69 \\
$\begin{array}{l}\text { congenital defects* } \\
\text { Unexplained neonatal } \\
\text { death }\end{array}$ & 1 & 1.93 \\
\hline *First pregnancy-abortion and second preg- \\
$\begin{array}{l}\text { nancy-congenitally-malformed liveborn baby; } \\
\text { IUFD=Intrauterine foetal death }\end{array}$ \\
\hline
\end{tabular}


with the transmission routes increases as his or her age increases (21).

In the present study, the percentage of seropositivity was also assessed in relation to the number of $\mathrm{BOH}$. Table 3 clearly shows that there was no relationship between increase in the number of pregnancy wastages and seropositivity. This corroborates the observation of Borkakoty et al. (14). According to their study, the increase in the number of pregnancy wastages had no significant association with infection due to T. gondii (14). Women of childbearing age, with no previous exposure to Toxoplasma, are at a risk of acquiring acute infection during pregnancy, resulting in congenital toxoplasmosis (3). Women give birth to children with congenital infection only once (23). If the mother was infected by the parasite before the current pregnancy, babies do not suffer from congenital toxoplasmosis. Transplacental transmission from chronic infection does not occur (1).

Among the seropositive cases, abortion (51.92\%) was the commonest form of pregnancy wastage, followed by stillbirths/intrauterine foetal deaths (36.53\%), premature deliveries (7.69\%), congenital anomalies $(1.93 \%)$, and early unexplained neonatal deaths (1.93\%). Surpam et al. observed abortions in $27.27 \%$, intrauterine growth restriction in $9.37 \%$, intrauterine foetal death in $17.64 \%$, and preterm labour in $18.18 \%$ of cases (24). Kandle et al. reported similar results in their study; 42 (50\%) abortion cases were positive for anti-Toxoplasma antibodies (25). The result also partially matched with the observations of Bachhiwal et al. who reported that abortion was the commonest $(85.45 \%)$ form of pregnancy wastage, followed by congenital anomalies, stillbirths, and premature deliveries (16). However, the observation differed from that of Saxena et al. According to them, positivity was maximum in cases with history of congenital malformations (33.3\%), followed by cases with history of premature labour, abortions, and stillbirths (26). As such, the seroprevalence of toxoplasmosis was observed more among patients with BOH. Rai from Nepal examined 273 patients with various medical ailments and found that, of different groups, women with $\mathrm{BOH}$ had the highest seropositivity of Toxoplasma (27).

\section{Limitations}

Several potential limitations should be considered in interpreting the results of the present study. First, this is a hospital-based study in a rural set-up, which may not be representative of and applicable to the general population. Second, due to some constrains, we could not perform the IgG avidity test, which is needed to differentiate between acute/ recent and past infections in cases showing seropositivity for both IgM and IgG. Moreover, this is the first study on toxoplasmosis from this area. No previous data were available for reference. It can, however, provide a clear snapshot of the current situation, provide a reasonably precise and reliable estimate of the magnitude of risk, and may help improve the management and design of future studies to explore further.

\section{Conclusions}

The present study is directed at providing the profile of the seroprevalence of toxoplasmosis among antenatal women with and without $\mathrm{BOH}$ among the study subjects from Khammam, Andhra Pradesh, India. The findings revealed that the seropositivity of toxoplasmosis was significantly higher in the study group than that in the control group. There was a gradual increase in seroprevalence with advancing age, and the maximum seroprevalence was observed in the age-group of $>30$ years. The maximum seropositivity was observed in abortion cases.

The results indicate that toxoplasmosis is quite prevalent in and around Khammam. It is a welldocumented risk factor for $\mathrm{BOH}$ and may play a vital role in determining the foetal outcome. As the majority of acquired infections are subclinical, there is a need for regular screening of all pregnant women for this infection. The initiation of judicious treatment in time can, thus, be provided to prevent morbidity and mortality of infants born to such mothers.

\section{Recommendations}

Based on the findings of the study, we recommend the following steps for the appropriate management of this health problem:

- Routine serological testing is to be advised to all pregnant women with or without $\mathrm{BOH}$, attending the antenatal clinics for both Toxoplas$m a$-specific IgG and IgM antibodies.

- For women with negative results in both the tests, information and education relating to preventive measures are of paramount importance because they are at a high risk of acquiring a primary infection during pregnancy.

- Women who are showing both IgM and IgGpositive results, differentiation between recent infection and pre-existing infection may be done with the IgG avidity test and those showing low avidity be treated accordingly.

\section{REFERENCES}

1. Parija SC. Textbook of medical parasitology. 3rd ed. 
Chennai: All India Publishers and Distributers, 2008: 172-81.

2. Razzak AH, Wais SA, Saeid AY. Toxoplasmosis: the innocent suspect of pregnancy wastage in Duhok, Iraq. East Mediterr Health J 2005;11:625-32.

3. Pinard JA, Leslie NS, Irvine PJ. Maternal serologic screening for toxoplasmosis. J Midwifery Womens Health 2003;48:308-16.

4. McLeod R, Remington JS. Toxoplasmosis (Toxoplasma gondii). In: Behrman RE, Kliegman RM, Jenson $\mathrm{HB}$, editors. Nelson Textbook of pediatrics. 16th ed. Philadelphia, PA: WB Saunders, 2000:1054-62.

5. Singh S. Mother-to-child transmission and diagnosis of Toxoplasma gondii infection during pregnancy. Indian J Med Microbiol 2003;21:69-76.

6. Zargar AH, Masoodi SR, Laway BA, Sofi BA, Wani AI. Seroprevalence of toxoplasmosis in women with repeated abortions in Kashmir. J Epidemiol Community Health 1998;52:135-6.

7. Flegr J, Preiss M, Klose J, Havlícek J, Vitáková M, Kodym P. Decreased level of psychobiological factor novelty seeking and lower intelligence in men latently infected with the protozoan parasite Toxoplasma gondii Dopamine, a missing link between schizophrenia and toxoplasmosis. Biol Psychol 2003;63:253-68.

8. Vaughan JP, Morrow RH, editors. Manual of epidemiology for district health management. Geneva: World Health Organization, 1989:175-8.

9. Coêlho RA, Kobayashi M, Carvalho LB, Jr. Prevalence of IgG antibodies specific to Toxoplasma gondii among blood donors in Recife, northeast Brazil. Rev Inst Med Trop Sao Paulo 2003;45:229-31.

10. Savoia MC. Bacterial, fungal and parasitic diseases. In: Burrow GN, Ferris TF, editors. Medical complications during pregnancy. 5th ed. Philadelphia, PA: WB Saunders, 1999:295-335.

11. Singh S, Nautiyal BL. Seroprevalence of toxoplasmosis in Kumaon region of India. Indian J Med Res 1991;93:247-9.

12. Thapliyal N, Shukla PK, Kumar B, Upadhyay S, Jain G. TORCH infection in women with bad obstetric history-a pilot study in Kumaon region. Indian J Pathol Microbiol 2005;48:551-3.

13. Singh S, Pandit AJ. Incidence and prevalence of toxoplasmosis in Indian pregnant women: a prospective study. Am J Reprod Immunol 2004;52:276-83.
14. Borkakoty BJ, Borthakur AK, Gohain M. Prevalence of Toxoplasma gondii infection amongst pregnant women in Assam, India. Indian J Med Microbiol 2007; 25:431-2.

15. Singh KT, Dangvela RL. Toxoplasmosis in high risk pregnancies. J Obstet Gynaecol India 1992;42:774-7.

16. Bachhiwal R, Singhal A, Vyas L, Risni S, Bithu R, Hooja S. Seroprevalence and role of toxoplasmosis in pregnancy wastage. In: Proceedings of the XXXI Annual Congress of Indian Association of Medical Microbiologists. Mangalore: Kasturba Medical College, 2007:188.

17. Yasodhara P, Ramalakshmi BA, Sarma MK. A new approach to differentiate recent vs chronic toxoplasma infection: avidity ELISA in toxoplasma serology. Indian J Med Microbiol 2001;19:145-8.

18. Yasodhara P, Ramalakshmi BA, Lakshmi V, Krishna TP. Socioeconomic status and prevalence of toxoplasmosis during pregnancy. Indian J Med Microbiol 2004;22:241-3.

19. Devi Kh S, Devi YG, Singh NS, Singh AM, Singh ID. Seroprevalence of TORCH in women with still birth in RIMS hospital. J Med Soc 2008;22:2-4.

20. Sandhu SK, Singh J, Mann H, Kaur H. Toxoplasmosis and pregnancy wastage. J Obstet Gynaecol India 1994;44:194-8.

21. Spalding SM, Amendoeira MR, Klein CH, Ribeiro LC. Serological screening and toxoplasmosis exposure factors among pregnant women in south of Brazil. Rev Soc Bras Med Trop 2005;38:173-7.

22. Mittal V, Bhatia R, Singh VK, Sehgal S. Prevalence of toxoplasmosis in Indian women of child bearing age. Indian J Pathol Microbiol 1995;38:143-5.

23. Palmer SR, Soulsby L, Simpson DIH. Zoonoses. New York, NY: Oxford University Press, 1998:579-92.

24. Surpam RB, Kmlakar UP, Khadse RK, Qazi MS, Jalgaonkar SV. Serological study for TORCH infections in women with bad obstetric history. J Obstet Gynaecol India 2006;56:41-3.

25. Kandle SK, Vhawal SS, Tolenure PB, Jahagirdar VL. Toxoplasmosis: its role in abortion and primary infertility. J Obstet Gynaecol India 1995;45:197-9.

26. Saxena K, Bano I, Agarwal K. Incidence of toxoplasmosis in cases of bad obstetric history. J Obstet Gynaecol India 1993;43:703-6.

27. Rai SK, Upadhyay MP, Shrestha HG. Toxoplasma infection in selected patients in Kathmandu, Nepal. Nepal Med Coll J 2003;5:89-91. 